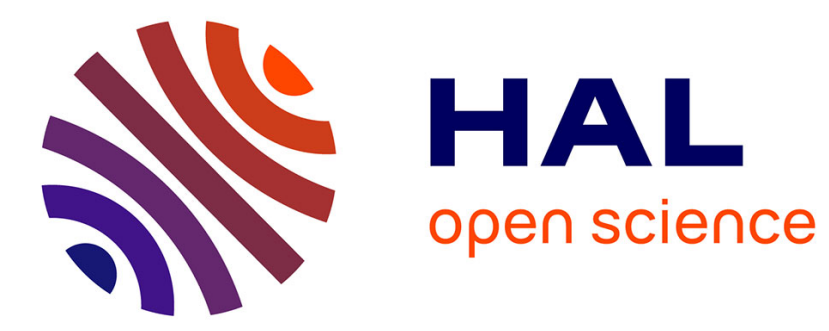

\title{
local analysis of heat transfer inside corrugated channel
}

Michel Gradeck, Bertrand Hoareau, Michel Lebouché

\section{To cite this version:}

Michel Gradeck, Bertrand Hoareau, Michel Lebouché. local analysis of heat transfer inside corrugated channel. International Journal of Heat and Mass Transfer, 2005, 48 (10), pp.1909-1915. 10.1016/j.ijheatmasstransfer.2004.12.026 . hal-01579174

\section{HAL Id: hal-01579174 \\ https://hal.univ-lorraine.fr/hal-01579174}

Submitted on 30 Aug 2017

HAL is a multi-disciplinary open access archive for the deposit and dissemination of scientific research documents, whether they are published or not. The documents may come from teaching and research institutions in France or abroad, or from public or private research centers.
L'archive ouverte pluridisciplinaire HAL, est destinée au dépôt et à la diffusion de documents scientifiques de niveau recherche, publiés ou non, émanant des établissements d'enseignement et de recherche français ou étrangers, des laboratoires publics ou privés. 


\title{
Local analysis of heat transfer inside corrugated channel
}

\author{
B. Hoareau*, M. Gradeck and M. Lebouché \\ LEMTA, CNRS UMR 7563, 2 avenue de la Forêt de Haye, BP 160, \\ 54504 Vandoeuvre-Les-Nancy, FRANCE \\ *Corresponding author : bhoareau@ensem.inpl-nancy.fr
}

\begin{abstract}
:
Experiments are performed to study effects of hydrodynamic conditions on the enhancement of heat transfer for single phase flow. These experiments have been conducted for a wide range of Reynolds numbers, $(0<\operatorname{Re}<7500)$ in order to obtain the different regimes from steady laminar to turbulent. A two-dimensional corrugated test section which has been instrumented with thermocouples can be heated by electrical cartridges. The local temperature measurements are used to evaluate the local and global heat transfer coefficient of the wavy heat exchanger. As expected, the heat transfer is always higher than those in rectangular channel; it is essentially due to the mixing induced by the recirculation in the wake of the corrugations.
\end{abstract}

\section{Nomenclature}

$A_{L} \quad$ Ratio of the area of the plate to its projected oneD

$\mathrm{D}_{\mathrm{h}} \quad$ Hydraulic diameter $(m)$

e Thickness of the channel $(m)$

Friction factor

$h \quad$ Convective heat transfer coefficient $\left(W \cdot m^{-2} \cdot K^{-1}\right)$

L Channel length $(m)$

$\mathrm{Nu} \quad$ Nusselt number, $N u=\frac{h D_{h}}{\lambda}$ 
Pr Prandtl number, $\operatorname{Pr}=\frac{\mu C_{p}}{\lambda}$

$\operatorname{Re} \quad$ Reynolds number, $\operatorname{Re}=\frac{\rho v D_{h}}{\mu}$

S Wall velocity gradient $\left(s^{-1}\right)$

$S^{\prime} \quad$ Plate's surface $\left(m^{2}\right)$

$T_{\text {in }}, T_{\text {out }} T_{p}, T_{\infty}$ Inlet, outlet, wall and bulk temperature $\left({ }^{\circ} \mathrm{C}\right)$

$\rho \quad$ Density $\left(\mathrm{kg} . \mathrm{m}^{-3}\right)$

$\lambda \quad$ Thermal conductivity $\left(W \cdot m^{-1} \cdot K^{-1}\right)$

$\mu \quad$ Dynamic viscosity $($ Pa.s $)$

$\varphi \quad$ Local heat flux density $\left(W . m^{-2}\right)$

$\Phi \quad$ Global power supply $(W)$

\section{1-Introduction}

The optimal design of heat exchangers is required to increase energy savings. The way to improve the global performances of plate heat exchangers is to find efficient heat transfer surfaces which do not induce much pressure loss. Using corrugated plates is a suitable method to increase the compactness which is needed for automotive, space and aeronautic devices. Besides, the wavy geometries are known to enhance the heat transfer by breaking and destabilizing the thermal boundary layer. So, corrugated surfaces serve as turbulence promoters to increase the local heat and mass transfer. For example, corrugated plates are broadly used in food industries where the two main restrictions are (i) to avoid the burnout of 
the fluid because of the heterogeneity of the heat transfer to the wall and (ii) to allow a good mixing of the fluid. The literature is rich in numerical or experimental studies.

In the eighties, Sparrow et al [1], having worked with water, studied the effects of the rounding of the corrugation on the heat transfer enhancement for a wide range of Reynolds numbers $(2000<\operatorname{Re}<33000)$ and for $4<\operatorname{Pr}<11$. For given flow parameters, they showed that the rounding induces a decrease of the Nusselt numbers. In the same way, and as expected, their visualization results show how smoothing the sharpness of corrugation is the best way to decrease the size of separated flow region. For sharp geometries, they proposed the following relation:

$$
N u=0,491 \cdot \operatorname{Re}^{0.632} \cdot \operatorname{Pr}^{0.3}
$$

Snyder et al [2] pointed out the increasing rate of heat transfer, in laminar and transitional flow regimes for $250<\mathrm{Re}<10000$ and for air or water flow. Comparing parallel plates performances with corrugated ones, they found that Nusselt numbers can be multiplied by a nine factor for the air flow and by a fourteen factor for the water flow. For Re $>250$, they correlated their results using relation (2) :

$$
N u=4+29,2 \cdot \ln \left[\frac{\left(\operatorname{Re} \cdot \operatorname{Pr}^{0.4}+1000\right)}{1200}\right]
$$

For steady laminar flow, Nishimura et al [3] showed that there was not significant enhancement of heat transfer compared to flat plates. Nevertheless, for turbulent flows, the use of corrugated plates brings a better heat exchange and a better mixing. 
Following the pioneering work of Savostin and Thikonov [4], Stasiek et al [5,6] used a new and original true-colour image processing of liquid crystal experimental technique to the study of temperature field and heat transfer coefficient. Their fluid of work was the air and their experimental set-up allowed Reynolds numbers ranging from 500 to $10^{4}$. For several undulation angles, they compared the experimental values of average Nussel number, local Nusselt number and friction factor. They observed that the Nusselt average values increase by about eighty percent for undulation angles ranging from 20 to 70 degrees whereas the friction coefficient increases by 3 times. They also investigated the distribution of local heat transfer and localised classic high values nearby the top of corrugation and weak values nearby the bottom of corrugation. Their experiments gave the following correlation for the Nusselt number:

$$
N u \sim \operatorname{Re}^{2 / 3}
$$

The dependence of the Nusselt number with the angle is given by this relation

$$
N u \approx \exp \left(\frac{\theta}{50^{\circ}}\right)
$$

Besides, they proposed a relation for the friction factor:

$$
f \approx \mathrm{Re}^{-1 / 2}
$$

Finally the dependence of the friction factor with the angle is given by this relation

$$
f=\exp \left(\frac{\theta}{20^{\circ}}\right)
$$

More recently, Béreiziat et al. [7,8] have determined the different flow regimes between corrugated plates using the polarographic method and a laser velocimeter. The different 
regimes are given in the table 1 . These results are in good agreement with those obtained by Hugonnot et al. [9]

Concerning the numerical works interested by the study of flow between corrugated plates, we can quote the work of Wang et al. [10]. These authors observed oscillating flow patterns for Reynolds numbers around 180. Their results are in good agreement with the experimental results of Béreiziat [7]. In steady regime, heat performances of corrugated and flat plates are similar. On the other hand, for transitional regime, they showed an increase in a factor 2.5 of the heat transfer coefficient.

Candel [11] reminds us that the transition from laminar regime to turbulent regime occurs by step. So, within the flow, small amplitude instability waves progressively appear. These waves, (also called Tollmien-Schlichting waves) are distorted by the flow and induce vorticity which is amplified. Blancher et al. [12], using a Galerkin spectral analysis, studied the effect of these instabilities on convective heat transfer in wavy channel. Their results show that the instabilities start for $\mathrm{Re}=90$. The solution of the energy equation with Galerkin analysis lead to several conclusions:

- The first one is the increase of the heat transfer (about $+80 \%$ compared to the straight geometry) just after the stagnation point.

- The second is that in unsteady flow, high vorticity gradient's region induces high heat transfer coefficients

- Another conclusion is that maximum amplitude of heat transfer occurs around the stagnation zones. 
Analog conclusions are reported in the works of Sawyers et al. [13]. These authors show that heat transfer inside corrugated channel (2D and 3D) is enhanced because of the recirculation zones behind the undulations.

For wavy channels, linear stability of 2D steady flow has been investigated by Cho et al. [14]. They found a critical Reynolds number value equal to about 80 for the $2 \mathrm{D}$ configuration, which is in good agreement with the previous studies.

Using a genetic algorithm, Fabbri [15] made an interesting optimization study of corrugated channels. He showed that the corrugated wall enhance the heat transfer when Prandtl and Reynolds numbers are not too low.

Niceno et al. [16] numerically (covolume method) studied a fluid of which the Prandtl number is equal to 0.7 (i.e. air like fluid) in sinusoidal wall configuration and arc-shapped channel. Concerning the sinusoidal geometry, they found a transition Reynolds number between 175 and 200. For equal or superior Reynolds numbers, they noticed an increase in the heat transfer. For lower values, the increase of heat transfer does not justify the use of corrugated plates.

Studying heat transfer in sinusoidal wavy passages for Reynolds numbers ranging from 200 to 800, Rush et al [17] found that there is a significant heat transfer enhancement for the laminar flow. They showed that the location of the onset of the heat transfer enhancement along the channel is a function of Reynolds number. This location moves towards the entrance of the channel as the Reynolds number increases. 
Finally, the numerical investigation of Wang et al [18] on forced convection in a wavy channel reveals a heat transfer enhancement with the Reynolds number but also with the amplitude of the wavelength. They showed that this enhancement corresponds not only to large amplitude wavelength ratios but also to Reynolds number high enough.

Many studies on the general performance of these plates can be found in the literature but there is still a lack of knowledge on the local structure of the flow and on its links to the transfer efficiency. The present work deals with the local study of the local temperature distribution at the wall and its link with the local flow structure. The heat transfer coefficient for a Newtonian fluid flow will also be considered, as well as the global heat transfer performances.

\section{Experimental set-up}

\subsection{Test loop}

Fig. 1 shows a schematic representation of the experimental loop used. Liquid water is conveyed in the loop by a centrifugal pump which is part of a thermoregulation machine. This thermoregulation machine can supply until $12 \mathrm{~kW}$, this allows us to keep the inlet temperature of the fluid at a given value. The temperatures can range from $5 \mathrm{C}$ to $95 \mathrm{C}$. A by-pass is placed in parallel to the thermoregulation machine to control the flow rate from 0 to $10^{-3} \mathrm{~m} 3 \cdot \mathrm{s}^{-1}$. A tank is used to supply water to the loop or to drain it outside the loop. An electromagnetic flow-meter is placed upstream from the test section. Two thermocouples (model T) and a differential pressure transducer are placed between the inlet and the outlet of the test section. A co-current heat exchanger, linked to a cooling system, is placed at the outlet of the test section for reducing the temperature of the fluid. 


\subsection{Test sections}

The test section consists of 2 opposite corrugated plates. The shape is made with a series of semi-circles $\left(\mathrm{R}_{1}=10 \mathrm{~mm}\right.$ and $\left.\mathrm{R}_{2}=2 \mathrm{~mm}\right)$ which are connected by straight segments. Fig. 2 describes the shape and the dimensions of the geometry. The main goal for using such geometry is to keep a nearly constant hydraulic diameter. The whole of corrugated plate is made of 8 undulations (the width is equal to $100 \mathrm{~mm}$ ). Gradeck et al. [19,20] and Béreiziat [7] have studied a geometry which only differs from our own one from a scale factor of 2.5 . Table 2 gives the characteristic dimensions of each of the two geometries.

For the two test sections, the equivalent hydraulic diameter is given by :

$$
D_{h}=\frac{2 \cdot e}{A_{L}}
$$

$A_{L}$ is the ratio between the developed area of the plate and that projected.

In our cases, this ratio is equal to 1,21 . The mean distance between the plates is of about 8 $\mathrm{mm}$ and the hydraulic diameter is equal to $13.2 \mathrm{~mm}$. A first test section is made of PMMA and allows flow visualizations. A second test section made of stainless steel can be heated with inserted electrical cartridges (Fig. 3). These heat sources can supply a maximal heat flux of about $62,5 \mathrm{~W} / \mathrm{cm}^{2}$. Nine embedded thermocouples allow measurement of the temperature evolution on a pitch of a corrugation (Fig. 3).

\subsection{Operating conditions and data reduction}

All the experiences have been made with demineralised water. At a fixed flow rate and a fixed inlet temperature, the application of a constant voltage to the electrical heating cartridges inserted in the bottom plate leads to an increase of the mean temperature of the plate. This temperature increases and finally reaches a constant value at thermal equilibrium. To avoid heat losses and to allow a better homogenization of the plate temperature, the bottom plate is 
insulated with glass wool. The real power density transmitted to the fluid is checked by an energy balance (Fig. 4 and 5). By assuming that the power density at the wall is constant on one corrugation and that the axial conduction in the plate is neglected, the local heat flux can be defined as $\varphi=\frac{\Phi}{S^{\prime}}$, where $S^{\prime}$ is the overall plate surface. Thus, the heat transfer coefficient is given by the following relation:

$$
h(x)=\frac{\frac{\Phi}{S^{\prime}}}{\left(T_{p}(x)-T_{\infty}(x)\right)}
$$

$x$ is the abscissa along the plate, $T_{p}(x)$ is the local temperature of the wall and $T_{\infty}(x)$ the local mean temperature of the fluid. We will consider that the variation of the mean temperature of the fluid between the inlet and the outlet of the system is linear.

$$
T_{\infty}(x)=\frac{T_{\text {out }}-T_{\text {in }}}{L} \cdot x+T_{\text {in }}
$$

The local Nusselt numbers can finally be estimated from the measurement of the local temperature.

$$
N u(x)=\frac{h(x) \cdot D_{h}}{\lambda}
$$

\section{Experimental results}

\section{1. temperatures}

Let us consider the influence of the forced convection on the temperature profiles. Several temperature profiles have been measured along the fifth corrugation (where the thermocouples have been inserted). On Fig. 6 and 7, one can observe the evolution of the local temperature at the wall over an undulation for one heating power density $\left(56,9 \mathrm{~kW} \cdot \mathrm{m}^{-2}\right)$, two inlet temperatures $\left(27^{\circ} \mathrm{C}\right.$ and $\left.70^{\circ} \mathrm{C}\right)$ and several flow rates. As expected, the value of the temperatures behind the top of the corrugation (where reverse flow takes place) are higher 
than those on the top. The difference between the weak and strong values can reach $15^{\circ} \mathrm{C}$. This is not negligible. Besides, we can notice that the temperature profiles are lightly asymmetric. This asymmetry depends on the direction of the flow and is due to the gradual increase of the fluid temperature and to the asymmetry of the flow field along the corrugation. The preceding figures showed a strong dependence of the temperature profiles with the imposed flow rate. One can observe that with low values of the flow rate, the difference of temperature between the upper and the bottom of the corrugation is of about of $20^{\circ} \mathrm{C}$ whereas for the higher flow rates this temperature difference is only $10^{\circ} \mathrm{C}$. From these strong variation of the temperature, over a $2 \mathrm{~cm}$ long undulation, we are able to predict a high disparity of the Nusselt number distribution.

\subsection{Local heat transfer}

Assuming the relations previously defined ( $§ 2.3)$, we can notice on Fig. 8 that the value of the local heat transfer coefficient can be three times greater on the upper part of the corrugation than on the bottom part of the corrugation. Indeed, at the top of the corrugation and nearby the detachment zone of the dynamic boundary layer where a new thermal boundary layer is nascent, the heat transfer coefficient is strongly influenced $\left(18 \mathrm{~kW} \cdot \mathrm{m}^{-2} \cdot \mathrm{K}^{-1}>h>5 \mathrm{~kW} \cdot \mathrm{m}^{-2} \cdot \mathrm{K}^{-1}\right)$ by the flow's effects. In the bottom location this heat coefficient is only lightly dependent on the flow rate. The values remain around $3000 W \cdot m^{-2} \cdot K^{-1}$. The corresponding Nusselt numbers are given on the Fig. 9.

Sawyers et al. [13], who made an analytical and numerical study, noted that the enhancement of local heat transfer is due to the presence of recirculation zones. With a similar geometry (two-dimensional), Gradeck et al $[19,20]$ have measured the evolution of the wall shear stress on a pitch of a corrugation. Their geometry is similar to our own one with a scale factor. If we 
compare the evolution of wall shear stress and Nusselt number, we can noticed that there is a very good agreement between the two experiments. This is an illustration of the analogy between mass transfer and heat transfer known as Reynolds analogy! As expected by the Reynolds analogy, we can notice that the Nusselt number is proportional to the wall velocity gradient to the power of third (Fig. 11).

$$
N u \propto S^{\frac{1}{3}}
$$

\subsection{Global heat transfer}

On the basis of the local heat transfer results, we are able to evaluate the average Nusselt number of the plate heat exchanger.

$$
\langle h\rangle=\frac{1}{N} \sum_{i=1}^{N} h(i)
$$

and

$$
\langle N u\rangle=\frac{1}{N} \sum_{i=1}^{N} N u(i)
$$

Fig. 12 shows the evolution of average Nusselt number and if we compare these results to the Dittus-Boelter correlation used for straight pipes, we can noticed that the corrugated plates strongly increase (of about 2 times) the heat transfer. We compared our experimental evaluation to the result of Sparrow [1] and Stasiek [5,6] (Table 3). Sparrow's relation and Stasiek's relation, whose geometries were not exactly the same than ours, overestimates our values.

\section{Concluding remarks}

The temperatures measured along a corrugation are a good signature of the general structure of the fluid flow. Under forced convection, we observed a very heterogeneous temperature distribution along the undulation. The study of the heat transfer coefficient shows a strong sensibility to convective effects at the top of the corrugation whereas in the bottom of the 
undulation, where the flow is disorganised, the convective effects are negligible. Finally we have pointed out a strong relation between the wall velocity gradient and the Nusselt number. Further investigations will be made on two-phase and boiling flow.

\section{References}

[1] E.M. Sparrow and L. M. Hossfeld, Effect of rounding of protruding edges on heat transfer and pressure drop in a duct, Int J. Heat Mass Transfer, 27 (1984) 1715-1723

[2] B. Snyder and K. T. Li and R. A. Wirtz, Heat transfer enhancement in a serpentine channel, Int J. Heat Mass Transfer, 36 (1993) pp 2965-2976

[3] T. Nishimura and Y. Kawamura, Three-dimensionality of Oscillatory Flow in a TwoDimensional Symmetric Sinusoidal Wavy-walled Channel, Experimental Thermal and Fluid Science, 10 (1995) 62-73

[4] A.F. Savostin and A.M. Tikhonov, Investigation of the characteristics of plate-type heating surfaces, Teploenergetica 17 (1970) 75-78

[5] J.A. Stasiek, Experimental studies of heat transfer and fluid flow across corrugatedundulated heat exchanger surfaces Int J. Heat Mass Transfer, 41 (1998) 899-914

[6] J.A. Stasiek and M.W. Collins and M. Ciofalo and P.E. Chew, Investigation of flow and heat transfer in corrugated passages -I Experimental results, Int J. Heat Mass Transfer, 39 (1996) 149-164

[7] D. Béreiziat, Structure locale de l'écoulement de fluides newtoniens et non newtoniens en canaux ondulés - Application à l'échangeur à plaques, $\mathrm{PhD}$ thesis, Institut National Polytechnique de Lorraine (1993). 
[8] D.Béreiziat, R. Devienne, Experimental characterization of newtonian and nonnewtonian fluid flows in corrugated channels, International Journal of Engineering Science 37 (1999) 1461-1479.

[9] P.Hugonnot, Etude locale de l'écoulement et performances thermohydrauliques à faible nombre de Reynolds d'un canal plan corrugué - Application aux échangeurs de chaleur à plaques, $\mathrm{PhD}$ thesis, Université Nancy I (1989)

[10] G. Wang and S. P. Vanka, Convective heat transfer in periodic wavy passages, Int J. Heat Mass Transfer 38 (1995) 3219-3230

[11] S. Candel, Mécanique des fluides - cours, Dunod editions, (1995)

[12] S. Blancher and R. Creff and P. Le Quere, Effect of Tolmien Schlichting wave on convective heat transfer in a wavy channel. Part 1: Linear analysis, International Journal of Heat and Fluid Flow, 19, 1999, pp 39-48

[13] D.R. Sawyers, M. Sen, H-C. Chang, Heat transfer enhancement in three-dimensional corrugated channel flow, Int. Journal of Heat and Mass Transfer, 43 (1998) 3559-3573

[14] Kie Joo Cho and Moon-Uhn Kim and Hyun Dong Shin,Linear stability of twodimensional steady flow in wavy-walled channels, Fluid Dynamics Research, 23 (1998) $349-370$

[15] G. Fabbri, Heat Transfer optimization in corrugated wall channels, Int. Journal of Heat and Mass Transfer, 43 (2000) 4299-4310

[16] B. Niceno and E. Nobile, Numerical analysis of fluid flow and heat transfer in periodic wavy channels, Int. J. of Heat and Fluid Flow 22 (2001) 156-167 
[17] T.A. Rush, T.A. Newell and A.M. Jacobi, An experimental study of flow and heat transfer in sinusoidal wavy passages, Int. J. of Heat and Mass Transfer, 42 (1999) $1541-1553$

[18] C.C. Wang and C.K. Chen, Forced convection in a wavy-wall channel, Int. J. of Heat and Mass Transfer 45 (2002) 2587-2595

[19] M. Gradeck, M. Lebouché, Wall shear measurements inside corrugated channels using the electrochemical technique, Experiments in Fluids 24 (1998) 17-26

[20] M.Gradeck, Structure de l'écoulement diphasique gaz-liquide dans les échangeurs à plaques corruguées, PhD thesis, Université Henri Poincaré Nancy I (1996) 


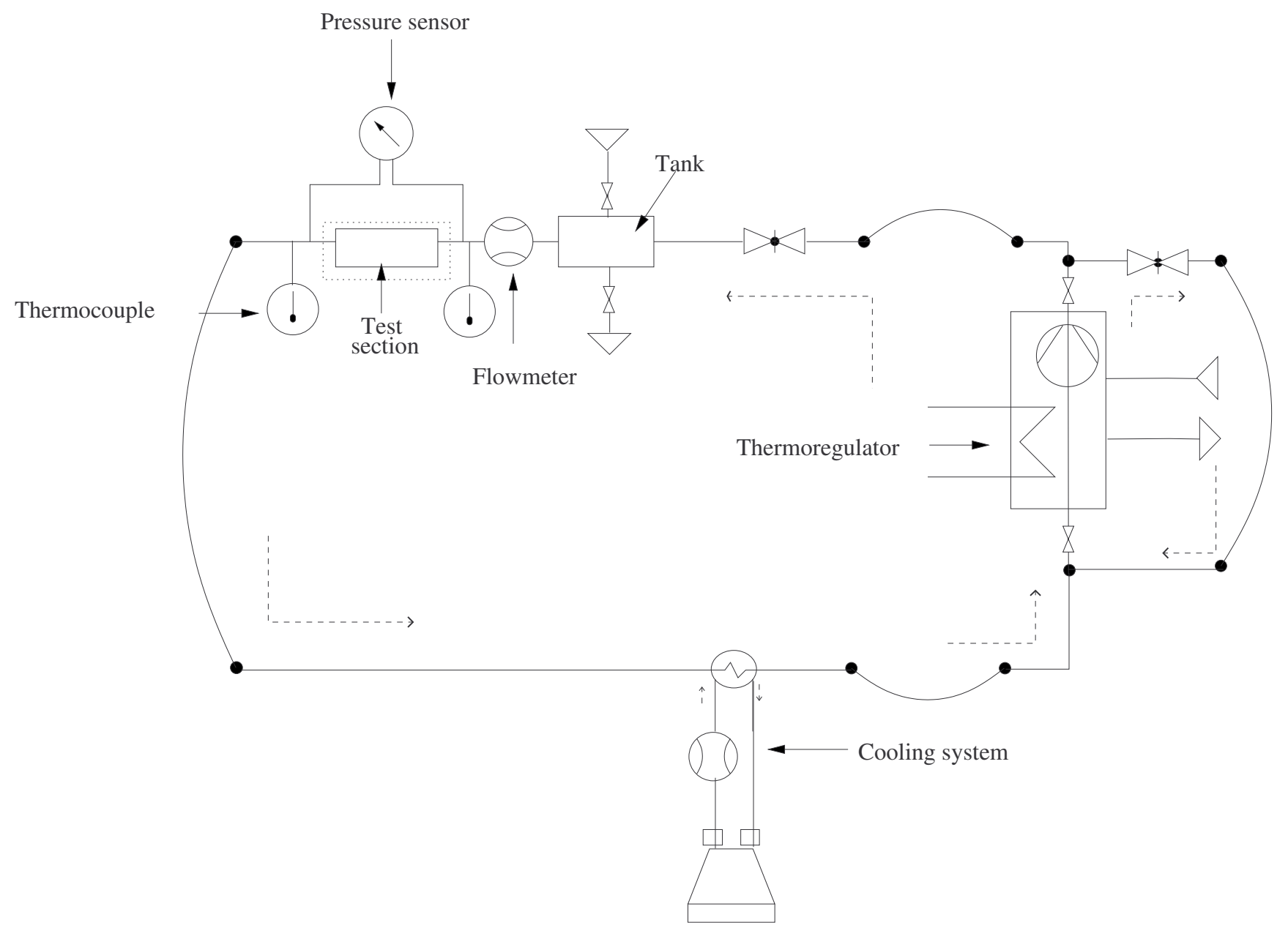

Fig. 1 - Schematic of the experimental loop 


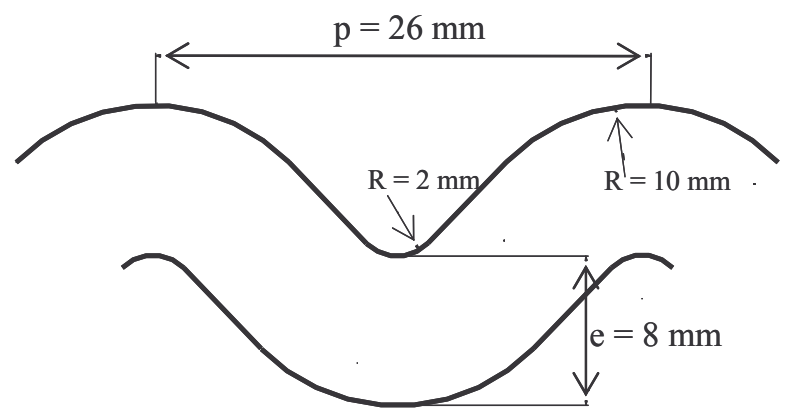

Fig. 2 - Shape and dimensions of the geometry 


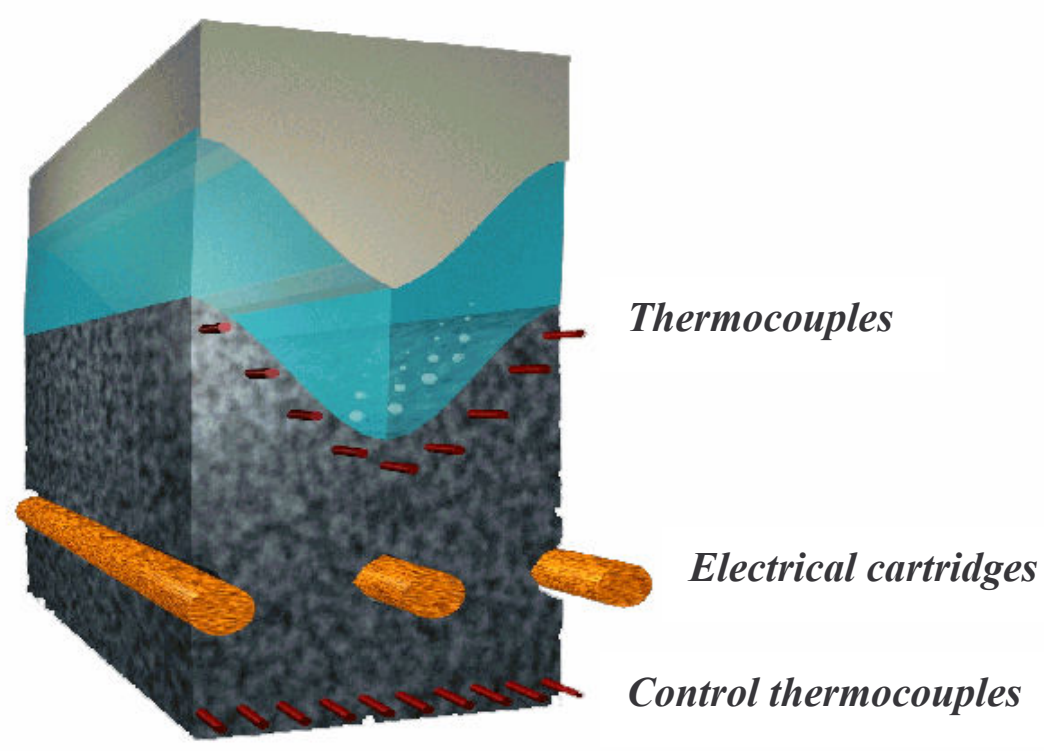

Fig. 3 - Location of the Thermocouples and the electrical cartridges along one corrugation 


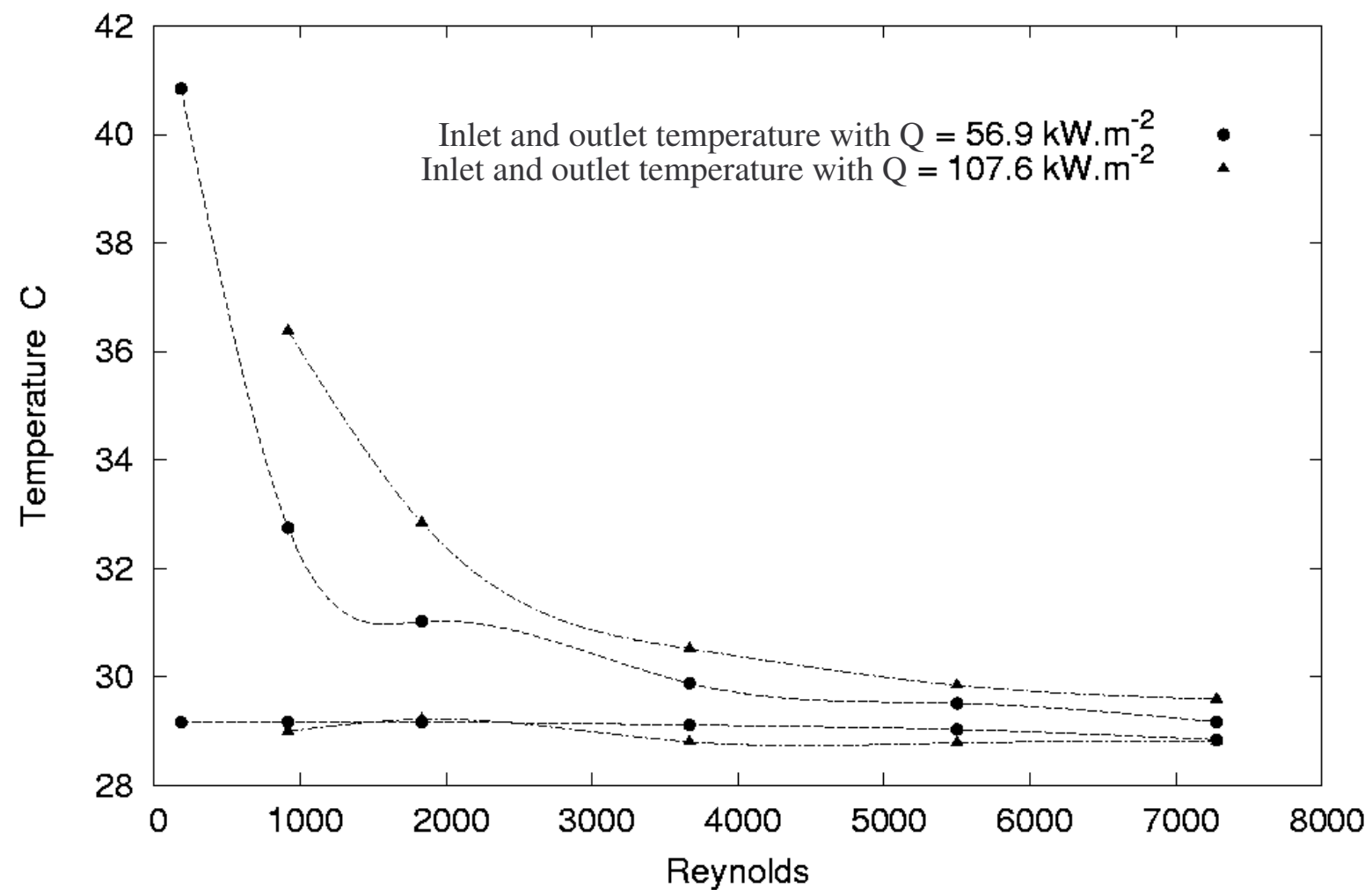

Fig. 4 - Energy balance - Variation of the inlet $\left(T_{i n} \sim 29^{\circ} \mathrm{C}\right)$ and outlet temperatures 


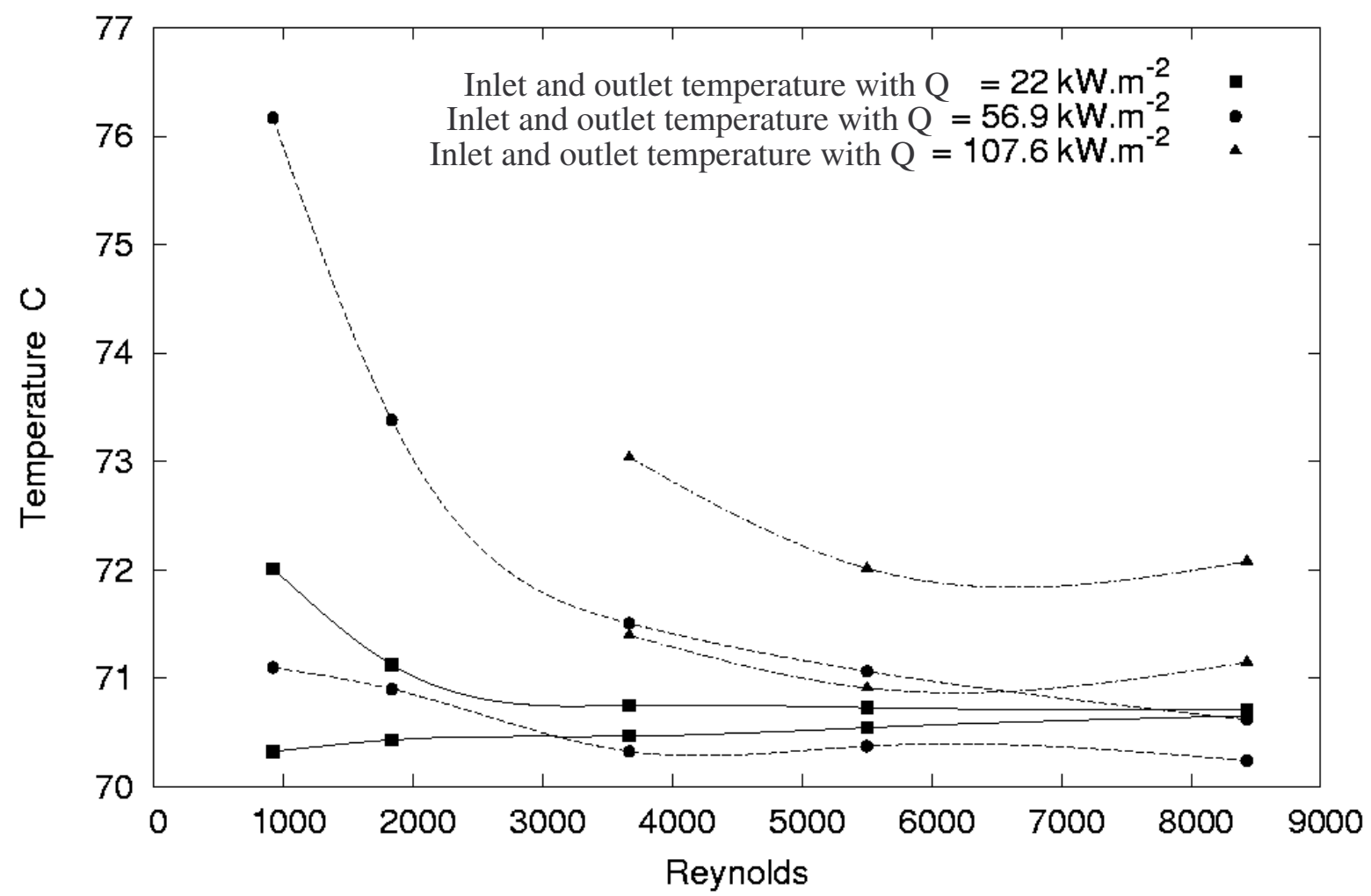

Fig. 5 - Energy balance - Variation of the inlet $\left(T_{i n} \sim 70^{\circ} \mathrm{C}\right)$ and outlet temperatures 


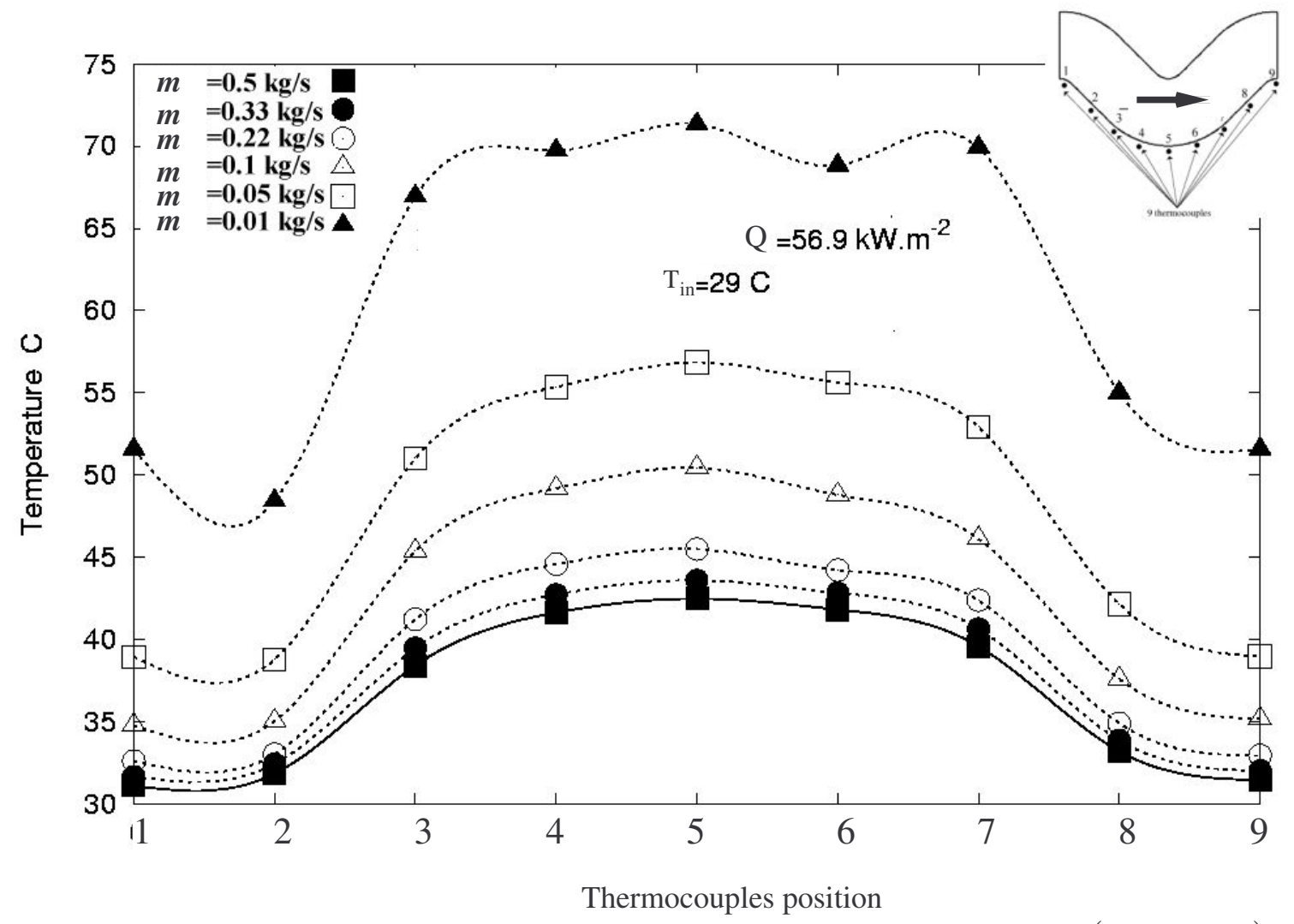

Fig. 6- Variation of the temperature's profiles for different flow rates $\left(T_{\text {in }}=29^{\circ} \mathrm{C}\right)$ 


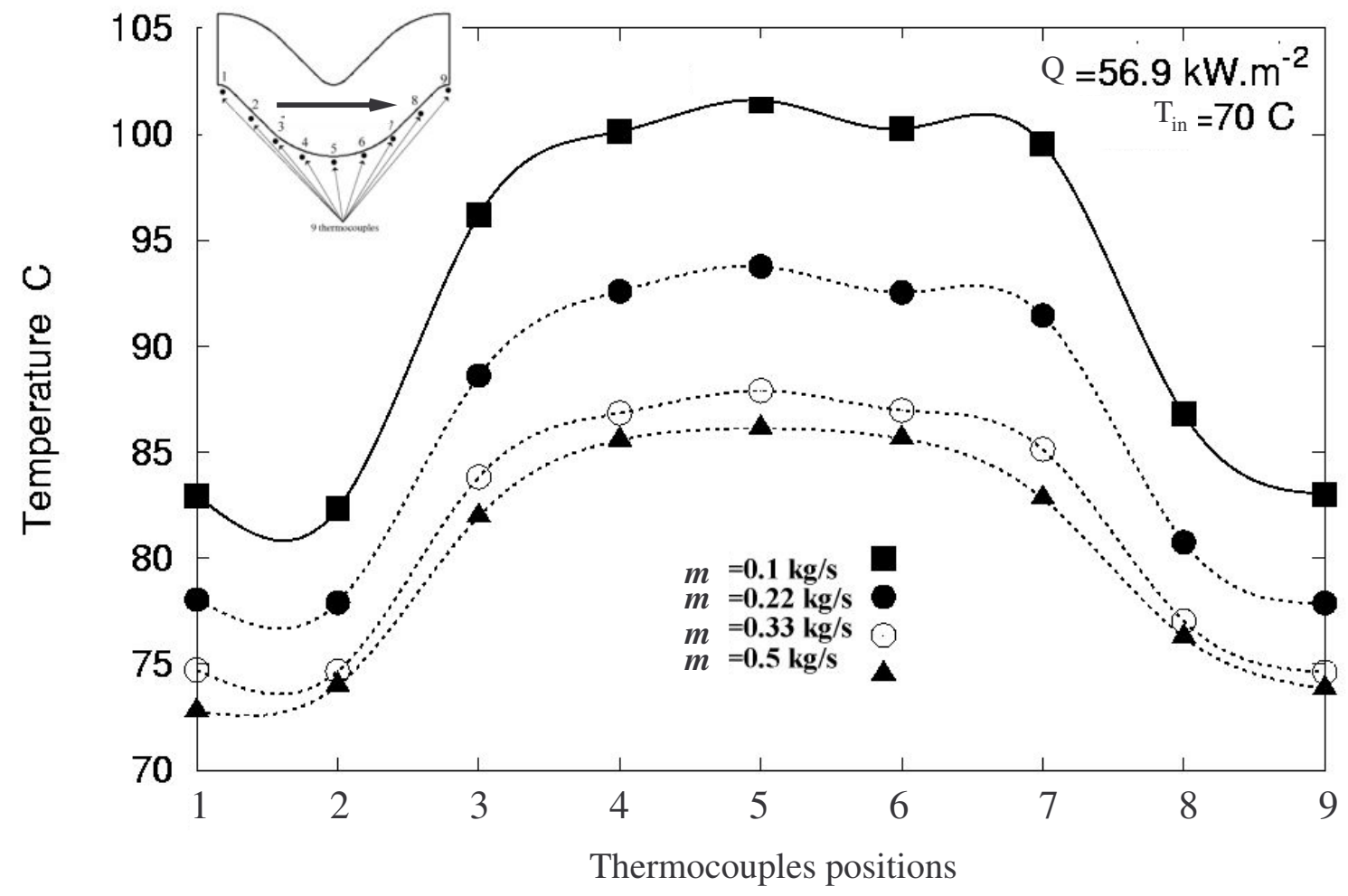

Fig. 7- Variation of the temperature's profiles for different flow rates $\left(T_{i n}=70^{\circ} \mathrm{C}\right)$ 


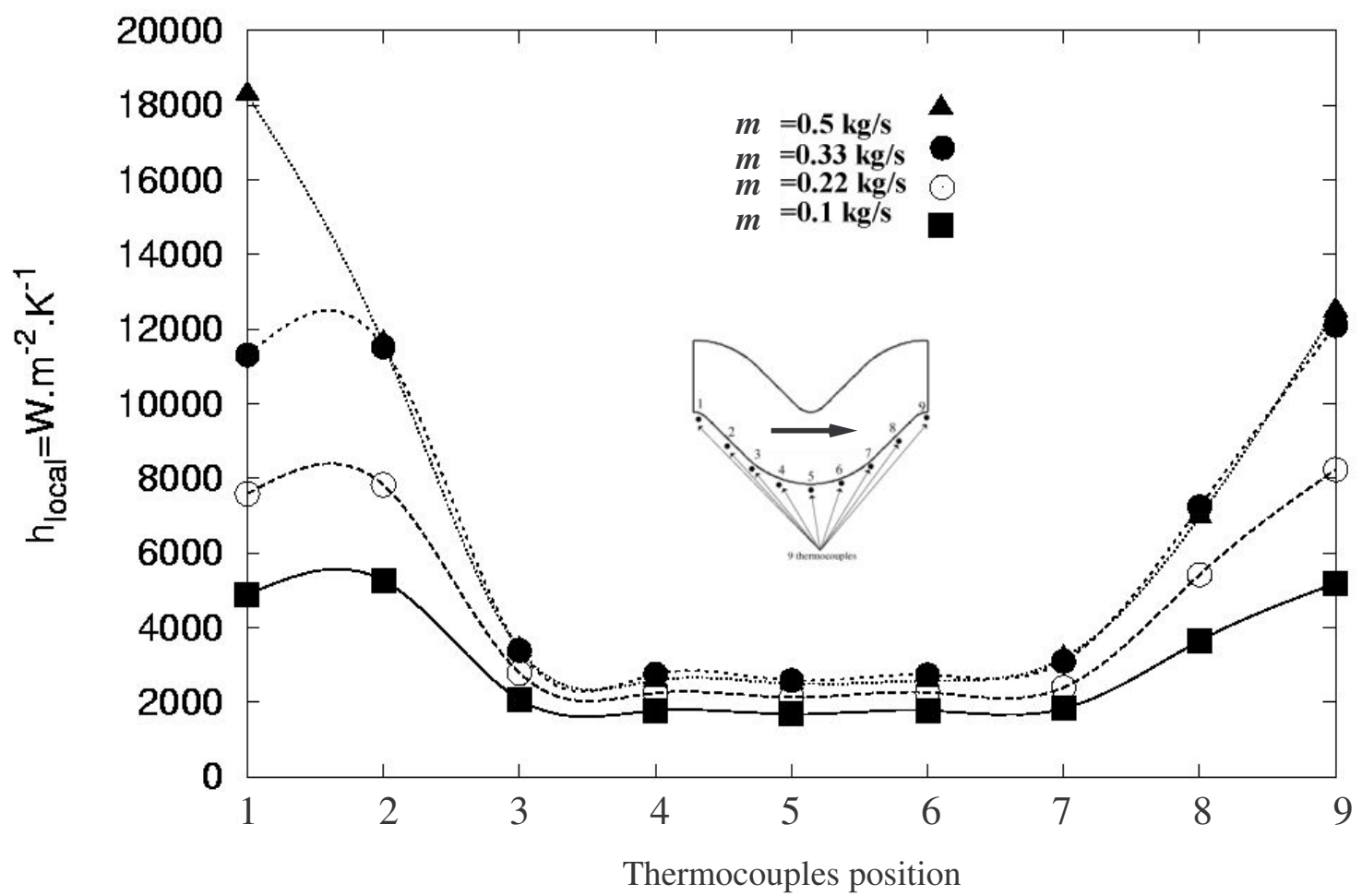

Fig. 8- Evolution of the heat transfer coefficient $-T_{\text {in }}=70^{\circ} \mathrm{C}$ and $Q=56.9 \mathrm{~kW} \cdot \mathrm{m}^{-2}$ 


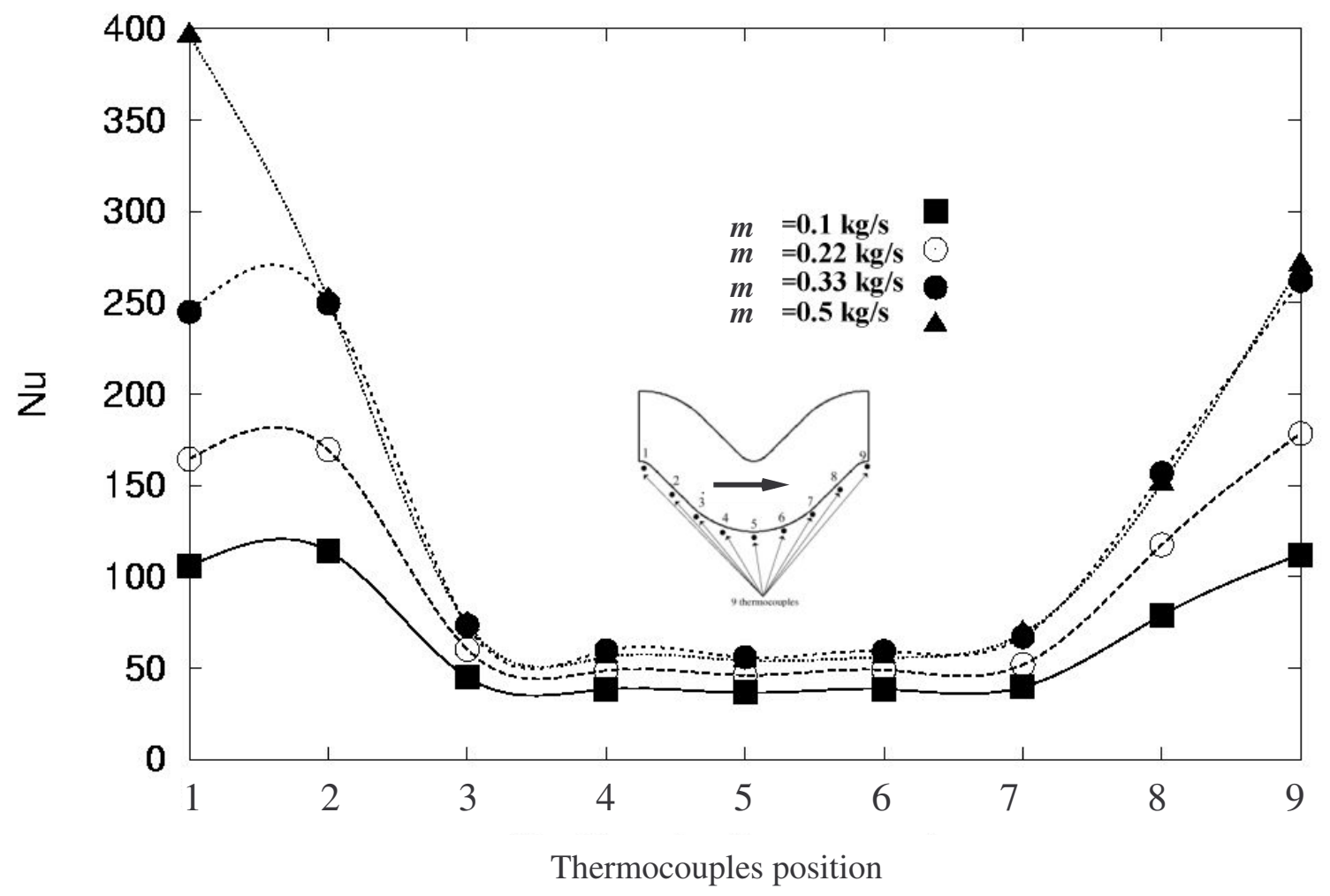

Fig. 9- Evolution of the Nusselt number $-T_{i n}=70^{\circ} \mathrm{C}$ and $Q=56.9 \mathrm{~kW} \cdot \mathrm{m}^{-2}$ 


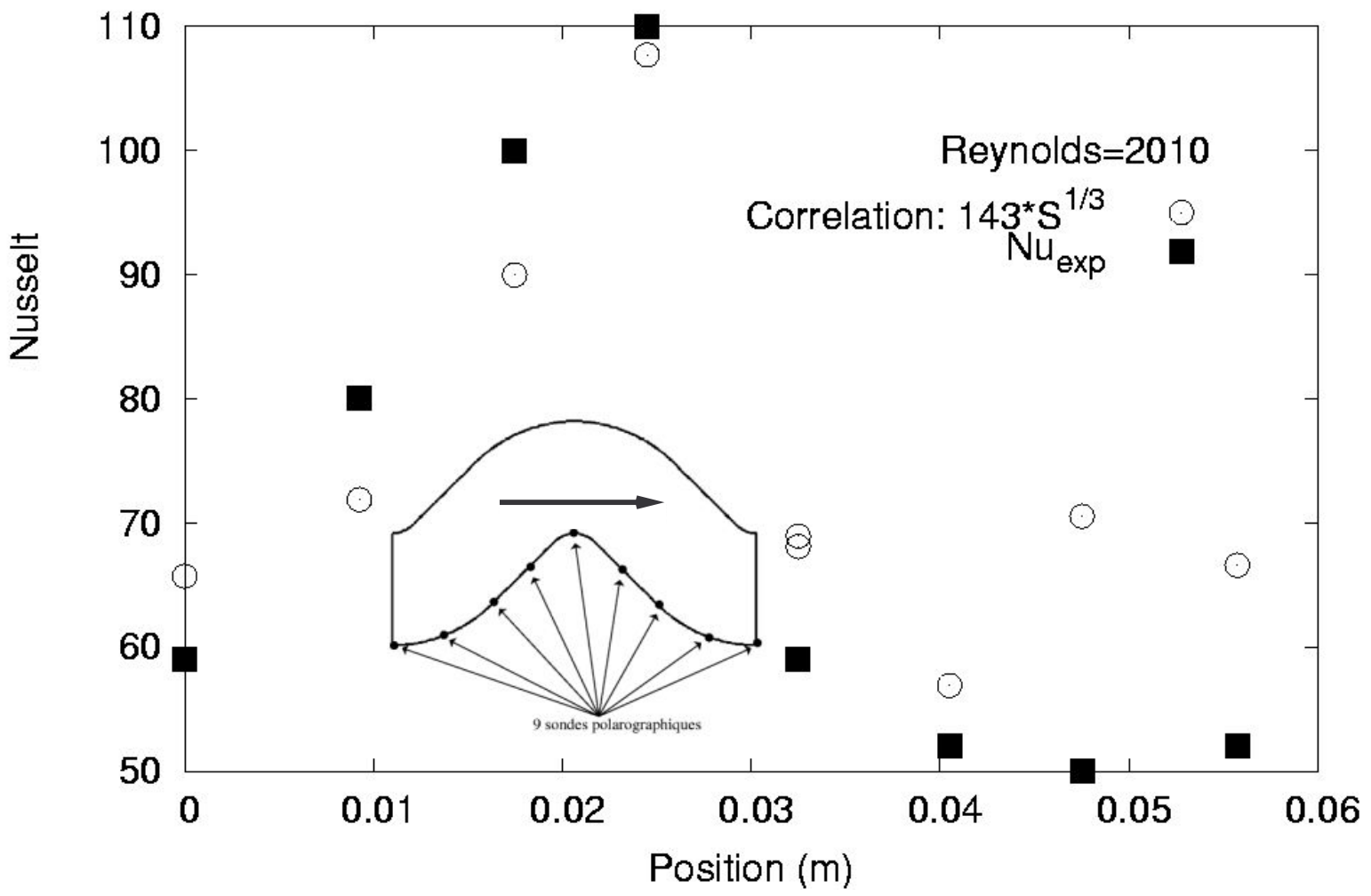

Fig. 10-Comparison between the evolution of the Nusselt number and the wall shear stress $S$ power of third (experiments of Gradeck et al. [20]) 


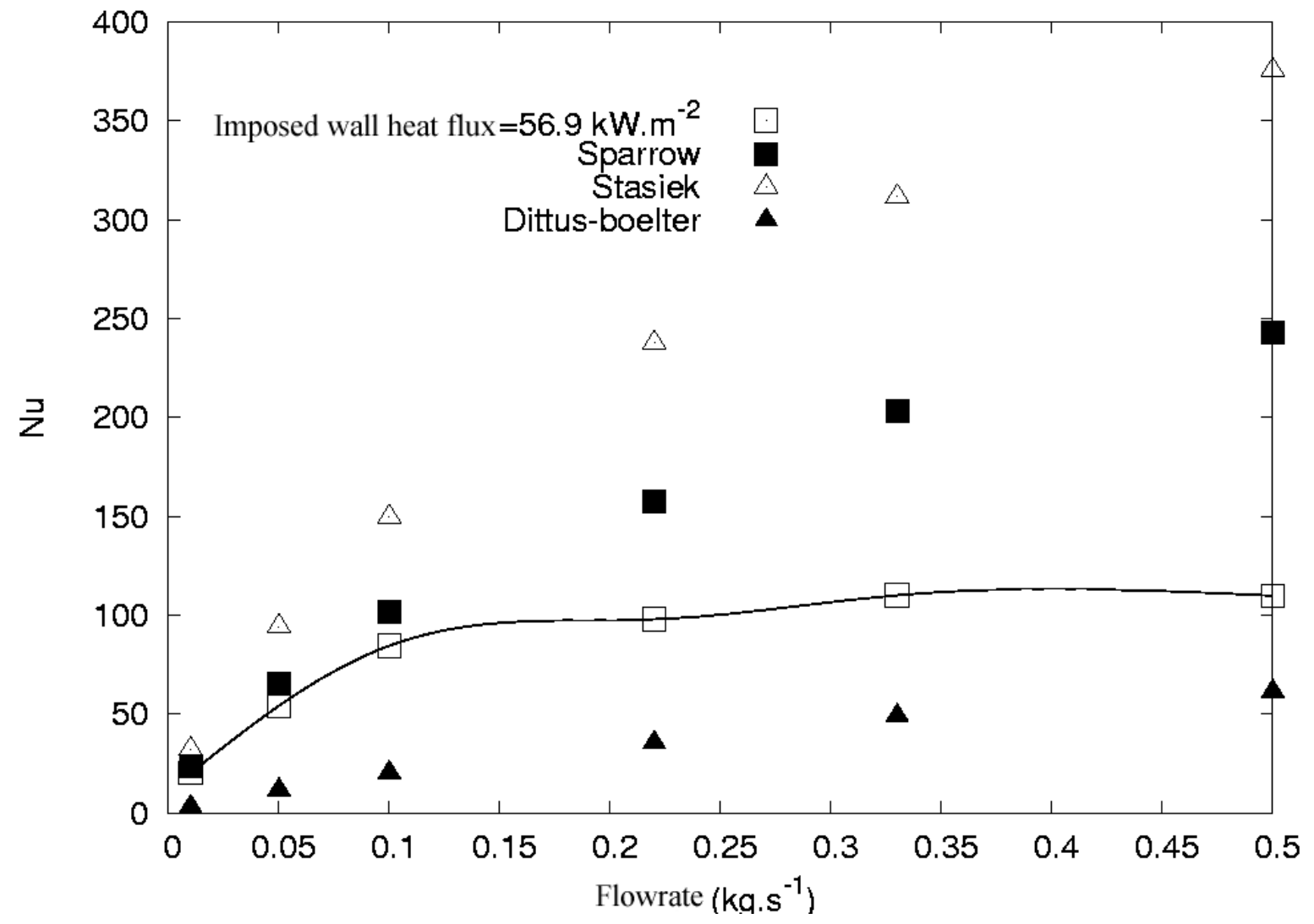

Fig. 11- Evolution of the average Nusselt number with the flow rate 


\begin{tabular}{|c|c|c|}
\hline Reynolds & Regime & Note \\
\hline $20<\operatorname{Re}$ & Laminar & \\
\hline $20<\operatorname{Re}<100$ & Laminar & Stabilized recirculation \\
\hline $100<\operatorname{Re}<200$ & Transitional & Instable recirculation \\
\hline $200<\operatorname{Re}<2000$ & Transitional & $\begin{array}{c}\text { Vortices (Von } \\
\text { Karmann instabilities) }\end{array}$ \\
\hline $\operatorname{Re}>2000$ & Turbulent & \\
\hline
\end{tabular}

Table 1 - Flow Regimes inside corrugated plates 


\begin{tabular}{|c|c|}
\hline $\begin{array}{c}\text { Gradeck/Béreiziat } \\
\text { Geometry }\end{array}$ & Our Geometry \\
\hline $\mathrm{e}=20 \mathrm{~mm}$ & $\mathrm{e}=8 \mathrm{~mm}$ \\
\hline $\mathrm{p}=65 \mathrm{~mm}$ & $\mathrm{p}=26 \mathrm{~mm}$ \\
\hline
\end{tabular}

Table 2 - Characteristic dimensions of the geometries 


\begin{tabular}{|c|c|}
\hline Correlation of Sparrow & $N u=0,491 \cdot \operatorname{Re}^{0.632} \cdot \operatorname{Pr}^{0.3}$ \\
\hline Correlation of Dittus-Boelter & $N u=0,023 \cdot \operatorname{Re}^{0.8} \cdot \operatorname{Pr}^{0.4}$ \\
\hline Correlation of Stasiek & $N u \alpha \mathrm{Re}^{\frac{2}{3}}$ \\
\hline
\end{tabular}

Table 3 - Correlations of the Nusselt number 